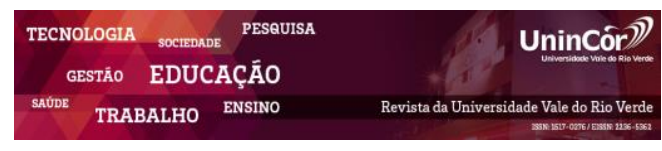

Revista da Universidade Vale do Rio Verde ISSN: 1517-0276 / EISSN: 2236-5362 v. $17 \mid$ n. 1 | Ano 2019

Clecilene Gomes de Carvalho Universidade Vale do Rio Verde clecilene@globo.com

Dejanir José Campos Junior Universidade Vale do Rio Verde dejanir.junior@unincor.edu.br

Gleicione Aparecida Dias Bagne de Souza Universidade Vale do Rio Verde gleici@unincor.edu.br

\section{NEUROCIÊNCIA: UMA ABORDAGEM SOBRE AS EMOÇÕES E O PROCESSO DE APRENDIZAGEM}

\section{RESUMO}

As emoções fazem parte da evolução da espécie humana e, obviamente, se constituem parte fundamental da aprendizagem humana. Sem dispor de funções de autorregulação emocional, a história da Humanidade seria um caos e a aprendizagem um drama indescritível, as emoções tomariam conta das funções cognitivas e os seres humanos só saberiam agir de forma impulsiva, excitável, eufórica, episódica e desplanificada. Eis então a razão de o porquê o cérebro humano integra inúmeros e complexos processos neuronais de produção e de regulação das respostas emocionais. O desencadeamento das emoções colabora, ainda, para a formação de memórias, desde que exista suficiente emoção numa determinada experiência, somos capazes de registrar na memória e de ativá-la, posteriormente. A neurociência compreende o estudo do controle neural das funções vegetativas, sensoriais e motoras; dos comportamentos de locomoção, reprodução e alimentação; e dos mecanismos da atenção, memória, aprendizagem, emoção, linguagem e comunicação. Portanto, o objetivo deste artigo de revisão é pesquisar em que as descobertas da neurociência em relação às emoções humanas podem colaborar com o processo de aprendizagem. Espera-se que seja o primeiro passo para que pesquisas de campo sejas implementadas e que a multidisciplinaridade de neurociências e ciências possam enriquecer o aprender.

Palavras-chave: Neurociência. Emoções. Memória Aprendizagem.

\section{NEUROSCIENCE: AN APPROACH TO ABOUT EMOTIONS AND THE LEARNING PROCESS}


human emotions can collaborate with the learning process. It is expected to be the first step for field research to be implemented and the multidisciplinarity of neuroscience and science to enrich learning.

Keywords: Neuroscience. Emotions. Memory. Learning.

\section{Recebido em: 25/10/2018 - Aprovado em: 21/03/2019 - Disponibilizado em: 15/07/2019}

\section{INTRODUÇÃO}

Ainda no século XIX, começaram a surgir estudos mais aprofundados e sistemáticos dos processos cerebrais envolvidos nas emoções. Pesquisadores como o psicólogo americano William James (1842-1910) e o fisiologista dinamarquês Carl Lage (1834-1900), propuseram que as emoções não existem sem manifestações fisiológicas e comportamentais. (...) Mas foi no final da década de 1920 que o fisiologista americano Walter Cannon (1871-1945) e seu aluno Philip Bard (1898-1977), propuseram mais objetivamente o sistema nervoso central como o causador, em paralelo, tanto da experiência subjetiva emocional como de suas manifestações fisiológicas e comportamentais. (...) A teoria Cannon-Bard foi a primeira tentativa concreta de elucidar as bases neurais das emoções. (...) Foi quando o anatomista americano Jamez Papez (1883-1958) mudou o eixo de raciocínio de centros isolados de coordenação emocional para o conceito de "sistema" ou circuito, que recebeu o nome de circuito de Papez (LENT, 2010).

Evidências experimentais ulteriores permitiram a revisão das estruturas pertencentes ao circuito proposto por Papez, surgindo, assim, o conceito de sistema límbico (SL). Verificou-se, ainda, que o chamado sistema límbico tinha outras funções, pois suas estruturas estavam envolvidas não só com os processos emocionais e motivacionais, mas também com a memória, a aprendizagem e, ainda, com os controles visceral e neuroendócrino (COSENZA, 2012).

As emoções podem ser classificadas por "valência (positiva e negativa) e ainda por três grupos: as primaria ou básicas, as secundárias e as emoções de fundo" (LENT, 2010, p. 716).

$\mathrm{O}$ desencadeamento das emoções colabora, ainda, para a formação de memórias. Desde que exista suficiente emoção numa determinada experiência, somos capazes de registrar na memória e de ativá-la, posteriormente (ABRANTES, 2014).

As neurociências estudam os neurônios e suas moléculas constituintes, os órgãos do sistema nervoso e suas funções, e ainda as funções cognitivas e o comportamento que são resultantes da atividade dessas estruturas. Graças ao desenvolvimento e ao aperfeiçoamento de técnicas de neuroimagem, de eletrofisiologia, da neurobiologia molecular e ainda os achados no campo da genética e da neurociência cognitiva, o conhecimento neurocientífico cresceu muito nos últimos anos (COSENZA; GUERRA, 2011).

Portanto, o objetivo deste artigo de revisão é pesquisar sobre de que forma as descobertas da neurociência em relação às 
emoções humanas podem colaborar com o processo de aprendizagem. Espera-se que seja o primeiro passo para que pesquisas nesse sentido, sejam implementadas e que a multidisciplinaridade de neurociências e ciências possam enriquecer o aprender.

\section{MÉTODOS}

Para a construção do referencial bibliográfico foram priorizados artigos com data de publicação entre 2008 a 2018. A busca foi realizada nas bases de dados - Biblioteca Virtual em Saúde (BVS); Literatura Latino Americana e do Caribe em Ciências da Saúde (Lilacs) e Scientific Electronic Library Online (SciELO). Utilizaram-se os descritores "emoções" e "neurociências", que foram combinados com "aprendizagem" e "memória", utilizando os operadores booleanos "AND" ou "OR". A priori foi realizada a leitura dos resumos e os artigos que não mantinham relação com o tema proposto, formam descartados. Para as pesquisas foram considerados os artigos em língua inglesa e portuguesa que estavam disponibilizados na íntegra. Não foi considerada data de corte para a escolha dos livros para compor o referencial. (respostas autonômicas, comandadas pelo sistema nervoso central, SNC) e comportamentais detectáveis (respostas motoras)" (LENT, 2010, p. 715, 717) como: "aumento do estado de alerta, desassossego, dilatação da pupila, sudorese, lacrimejamento, alteração da expressão facial, entre outras" (COSENZA; GUERRA, 2011, p. 76). O que permite que ela seja analisada mais facilmente com os métodos da neurociência (LENT, 2010, p. 715).

As emoções conferem, portanto, o suporte básico, afetivo, fundamental e necessário às funções cognitivas e executivas da aprendizagem que são responsáveis pelas formas de processamento de informação mais humanas, verbais e simbólicas (FONSECA, 2016).

Segundo Lent (2010, p. 714), “as emoções negativas são mais conhecidas do que as positivas, talvez porque sejam mais ricas em manifestações fisiológicas".

As emoções podem ser classificadas por "valência (positiva e negativa) e ainda por três grupos: as primaria ou básicas, as secundárias e as emoções de fundo" (Quadro 1) (LENT, 2010, p. 716).

\section{REFERENCIAL TEÓRICO}

\subsection{EMOÇÕES E MEMÓRIA}

A emoção "é uma experiência subjetiva acompanhada de manifestações fisiológicas 
Quadro 1 - Classificação das emoções humanas por grupo e por valência.

\begin{tabular}{|l|l|l|}
\hline \multicolumn{2}{|c|}{ Classificação por grupo } \\
\hline Primárias/básicas & Secundárias & De fundo \\
\hline Alegria & Culpa & Ansiedade \\
Tristeza & Vergonha & Depressão \\
Medo & Orgulho & Calma \\
Nojo & & Tensão \\
Raiva & & \\
Surpresa & \multicolumn{2}{|c|}{ Classificação por valência } \\
\hline \multicolumn{2}{|c|}{} \\
\hline Emoções positivas & Amor, alegria, encantamento, amizade \\
\hline Emoções negativas & Ódio, tristeza, agonia, desespero, pânico, inveja, medo, ansiedade, raiva, \\
\hline
\end{tabular}

Fonte: Elaborado pelos autores.

As primárias se originam na rede de circuitos neurais do sistema límbico, a amígdala e o cíngulo são seus gatilhos (PEREIRA, et al, 2013), são inatas e não dependem de fatores sociais e culturais, são inerentes a todas as pessoas. As secundárias são influenciadas pelo contexto social e cultural, são aprendidas. Por meio delas o indivíduo obedece, ou não, as regras de comportamento que a sociedade lhes recomenda em cada lugar e época histórica. Já as emoções de fundo, referem-se a estados gerais de bem estar, ou mal estar (LENT, 2010, p. 716717).

\section{O desencadeamento das emoções} colabora, ainda, para a formação de memórias, desde que exista suficiente emoção numa determinada experiência, somos capazes de registrá-la na memória e de ativá-la, posteriormente (ABRANTES, 2014).

As emoções fazem parte da evolução da espécie humana e, obviamente, constituindo parte fundamental da aprendizagem humana. Sem dispor de funções de autorregulação emocional, a história da Humanidade seria um caos, e a aprendizagem um drama indescritível, as emoções tomariam conta das funções cognitivas e os seres humanos só saberiam agir de forma impulsiva, excitável, eufórica, episódica e desplanificada. Eis a razão porque o cérebro humano integra inúmeros e complexos processos neuronais de produção e de regulação das respostas emocionais (FONSECA, 2016, p. 35).

Áreas especiais nas regiões límbicas basais do cérebro determinam se uma informação é importante ou não e tomam a decisão subconsciente de armazenar a informação como um traço de memória sensibilizada ou suprimi-la (RAMOS, 2014).

Num clima de ameaça, de opressão, de vexame, de humilhação ou de desvalorização, o sistema límbico, situado no meio do cérebro, bloqueia o funcionamento dos seus substratos cerebrais superiores corticais, $\log$ das funções cognitivas de input, integração, planificação, execução e output, que permitem $\mathrm{o}$ acesso às aprendizagens simbólicas e à resolução de problemas complexos exclusivos da espécie humana (FONSECA, 2016, p. 19).

Em 1937, James Papez, neuroanatomista norte-americano, sugeriu que a atividade cognitiva no córtex afeta a expressão das emoções através de conexões com o hipotálamo e o hipocampo (mais, tarde denominado de 
circuito de Papez). Evidências experimentais ulteriores permitiram a revisão das estruturas pertencentes ao circuito proposto por Papez, surgindo, assim, o conceito de sistema límbico (SL). Verificou-se, ainda, que o chamado sistema límbico tinha outras funções (Quadro 2), pois suas estruturas estavam envolvidas não só com os processos emocionais e motivacionais, mas também com a memória, a aprendizagem e, ainda, com os controles visceral e neuroendócrino (COSENZA, 2012, pág. 114).

Quadro 2 - Estruturas do circuito neural envolvidas com os processos emocionais, motivacionais, memória, aprendizagem e, ainda, com os controles visceral e neuroendócrino.

Estruturas do circuito neural envolvidas com os processos emocionais, motivacionais, memória, aprendizagem e, ainda, com os controles visceral e neuroendócrino.

\begin{tabular}{|c|c|}
\hline Hipocampo & $\begin{array}{l}\text { Porção posterior parece estar envolvida nos processos de aprendizagem e memória. } \\
\text { Já o lóbulo anterior faz parte dos circuitos do lobo temporal envolvidos com a } \\
\text { emoção e o comportamento motivado. Ablação bilateral do hipocampo causa } \\
\text { amnésia retrograda, ou seja, a pessoa torna-se incapaz de aprender coisas novas, } \\
\text { mas é capaz de acessar a memória anterior ao evento (COSENZA, 2012, p. 116). }\end{array}$ \\
\hline Amígdala & $\begin{array}{l}\text { Relacionada com muitas funções emocionais, como o medo, comportamentos } \\
\text { agressivos, maternal, sexual e ingestivo (os atos de beber e comer). Está também } \\
\text { envolvida nos mecanismos de recompensa e suas implicações na motivação } \\
\text { (COSENZA, 2012, p. 117). }\end{array}$ \\
\hline Giro de cíngulo & $\begin{array}{l}\text { Está relacionado com a memória. Lesões singulares podem provocar apatia, } \\
\text { mutismo e mudanças de personalidade. Existem evidências de que possa estar } \\
\text { envolvido precocemente em patologias como a doença de Alzheimer, a } \\
\text { esquizofrenia, a depressão e o transtorno (COSENZA, 2012, p. 118). }\end{array}$ \\
\hline Septo & Relaciona-se à raiva, ao prazer e ao controle neurovegetativo. \\
\hline Cerebelo & $\begin{array}{l}\text { Historicamente conhecido por suas funções no controle da motricidade. Parece } \\
\text { estar envolvido, também, na aprendizagem motora e na memória correspondente a } \\
\text { memória de procedimentos. Estudos de envolvendo tecnologias de neuroimagem } \\
\text { têm mostrado alterações cerebelares em patologias como a esquizofrenia, o autismo } \\
\text { e a dislexia (COSENZA, 2012, p. 85). }\end{array}$ \\
\hline Hipotálamo & $\begin{array}{l}\text { Grande participação nos mecanismos reguladores dos processos emocionais e } \\
\text { motivacionais, além da função de controle da reprodução e do comportamento } \\
\text { sexual (COSENZA, 2012, p. 94). }\end{array}$ \\
\hline Tálamo & $\begin{array}{l}\text { Participa de processos emocionais e motivacionais e exerce papel na ativação e na } \\
\text { integração de atividades do córtex cerebral (COSENZA, 2012, p. 95). }\end{array}$ \\
\hline Área pré-frontal & $\begin{array}{l}\text { Está relacionada ao planejamento de comportamentos e pensamentos complexos, } \\
\text { expressão da personalidade, tomadas de decisões e modulação de comportamento } \\
\text { social (ESPERIDIAO-ANTONIO et al, 2008; COSENZA, 2012, p. 118). }\end{array}$ \\
\hline $\begin{array}{l}\text { Giro } \\
\text { parahipocampal }\end{array}$ & $\begin{array}{l}\text { Desempenha um papel importante na codificação e recuperação de memória } \\
\text { (ESPERIDIAO-ANTÔNIO et al, 2008). }\end{array}$ \\
\hline
\end{tabular}

Fonte: Elaborado pelos autores. 


\subsection{CONTRIBUIÇÕES DA NEUROCIÊNCIA NO PROCESSO DE APRENDIZAGEM}

As neurociências estudam os neurônios e suas moléculas constituintes, os órgãos do sistema nervoso e suas funções, e ainda as funções cognitivas e o comportamento que são resultantes da atividade dessas estruturas. Graças ao desenvolvimento e o aperfeiçoamento de técnicas neuroimagem, de eletrofisiologia, da neurobiologia molecular e ainda os achados no campo da genética e da neurociência cognitiva, o conhecimento neurocientífico cresceu muito nos últimos anos (COSENZA; GUERRA, 2011).

A neurociência compreende o estudo do controle neural das funções vegetativas, sensoriais e motoras; dos comportamentos de locomoção, reprodução e alimentação; e dos mecanismos da atenção, memória, aprendizagem, emoção, linguagem e comunicação (VENTURA, 2010).

Do ponto de vista das neurociências, as competências mais exigidas em nível cerebral para o aprendizado humano são listadas como cognitivas, técnicas, relacionais e emocionais (PEREIRA, et al, 2013).

As neurociências podem ser entendidas, em face de sua amplitude terminológica, como uma mescla de disciplinas que se ocupam do estudo do cérebro, tratando, mais especificamente, de seu desenvolvimento químico, estrutural, funcional e patológico. Complementando essa definição, as neurociências devem ser concebidas como um conjunto de ciências cujo objetivo é investigar não somente o sistema nervoso e seu respectivo funcionamento, como também as relações entre a atividade cerebral, comportamento e aprendizagem. As Neurociências fazem, portanto, referência a campos científicos e áreas de conhecimento diversas sem, necessariamente, ter interesses, enfoques ou métodos homogêneos (PORTES, 2015).

Do ponto de vista da neurociência, três tipos de memória estão envolvidos no aprendizado nas diferentes competências, sendo elas: memória semântica e episódica, memória procedimental e memória emocional (PEREIRA, et al, 2013). As "lembranças que temos dos eventos de nossa vida pessoal, tornam-se possíveis graças à memória episódica, enquanto a memória semântica é encarregada das lembranças que temos das coisas que nos rodeiam" (COSENZA, 2011). Competências técnicas relacionadas ao saber como fazer e habilidades são baseadas na memória procedimental (PEREIRA, et al, 2013). Os substratos neurológicos desses tipos de memória são encontrados no hipocampo e no córtex préfrontal. Se houver ablação dessas estruturas por algum motivo, qualquer pessoa se torna incapaz de adquirir novas cognições, mas seria capaz de realizar ações rotineiras ou repetitivas perfeitamente (COSENZA, 2011; PEREIRA, et al, 2013).

A aquisição das novas informações que poderão ser retidas na memória é chamada de aprendizagem. Memória é o processo de arquivamento seletivo das informações, que podemos evocar quando desejado, seja de forma consciente ou inconscientemente (LENT, 2011).

A memória é um processo relativo à persistência da aprendizagem que pode ser posteriormente evocada e esta compreende 
algumas subdivisões: a memória operacional ou de trabalho, onde se tem os registros transitórios que, mais tarde serão transformados em registros definitivos, sendo, por fim, armazenados na memória de longa duração (PORTES, 2015).

A memória é responsável pelo armazenamento de informações, bem como pela evocação daquilo que está armazenado. E a aprendizagem requer competências para lidar de forma organizada com as informações novas, ou com aquelas já armazenadas no cérebro, a fim de realizar novas ações (CARVALHO, 2010).

O sono é importante para a aprendizagem. É durante o sono que os mecanismos eletrofisiológicos e moleculares envolvidos na formação de sinapses mais estáveis estão em funcionamento. É como se o cérebro, durante o sono, passasse a limpo as experiências vividas e as informações recebidas durante o período de vigília, tornando mais estáveis e definitivas aquelas que são mais significativas (COSENZA; GUERRA, 2011). Em outras palavras, é durante o sono que o cérebro reorganiza suas sinapses, elimina aquelas em desuso e fortalece as importantes para os comportamentos do cotidiano do indivíduo (PORTES, 2015).

A Neurociência, que trata da cientificidade do cérebro, aponta a plasticidade cerebral como uma habilidade que este possui de se reorganizar a partir do aprendizado dos aprendizes, de acordo com meio em que está inserido.

Ao caracterizar essa habilidade cerebral, Lent (2010) afirma que o ambiente contribui para modificar a estrutura do sistema nervoso, ou seja, o cérebro responde às atividades promovidas pela ação do ambiente que o atinge. A partir dessa exposição, observamos que essa capacidade do cérebro de construir novas conexões neurais e modificar suas estruturas é que possibilita nosso aprendizado durante toda a nossa vida (LENT, 2010).

As neurociências têm mostrado que os processos cognitivos e emocionais estão profundamente entrelaçados. $\mathrm{O}$ fenômeno emocional tem raízes biológicas antigas e sua manutenção no processo evolutivo se deu pelo seu valor para a sobrevivência das espécies e dos indivíduos (COSENZA; GUERRA, 2011).

\begin{abstract}
A emoção dirige, conduz e guia a cognição, não se pode compreender a aprendizagem sem reconhecer o papel dela em tão importante função adaptativa humana. A interdependência da emoção e da cognição no cérebro é demonstrada pelas novas tecnologias de imagiologia do nosso órgão de aprendizagem e de interação social (FONSECA, 2016).
\end{abstract}

A Neurociência é essencial para o entendimento da aprendizagem e memória (RAMOS, 2014). Aprendizagem e desenvolvimento humanos são processos produtivos da atividade cerebral, ou seja, do sistema nervoso, portanto, pode-se afirmar que os estudos sobre a aprendizagem unem sobremaneira a Educação e as Neurociências (PORTES, 2015). Para entender profundamente o aprendizado, é impossível negligenciar o cérebro e como este funciona (RAMOS, 2014).

A aprendizagem, portanto, do ponto de vista biofisiológico, está associada a prazer, liberação de serotonina - neurotransmissor, memória, atenção voluntária focada e 
significação do que se está aprendendo (FERNANDES et al, 2015).

As neurociências vêm procurando explicações que possam aproximar o social do biológico e têm conseguido reafirmar que vivências mais intensas e significativas, no processo de aprender não só transformam, mas criam e recriam conexões cerebrais em qualquer época da vida humana (PEREIRA et al, 2013).

De acordo com Fonseca (2016) a aprendizagem com sucesso implica três componentes em interação sistêmica: a regulação emocional, o conhecimento consciente $\mathrm{e}$ as estratégias cognitivas. Ainda segundo o autor, a falta de integração entre os três componentes, apreender como corolário da experiência, tornase complicado, exatamente porque o indivíduo perde a capacidade de utilização do que conscientemente aprendeu. $\mathrm{O}$ que pode ser observado, com veemência, em casos patológicos que apresentam lesões no córtex pré-frontal ventromedial, sugerindo que o cérebro humano dispõe de várias áreas que conectam o conhecimento, isto é, as cognições com as emoções.

A partir da Neurociência e do conhecimento neurocientífico gerado por essa ciência pode-se abrir um diálogo com a educação no sentido de cooperação e parceria. A educação é caracterizada por um processo que envolve aprendizagem e esta é medida pelas propriedades estruturais e funcionais do sistema nervoso, especialmente o cérebro. Entretanto, deve-se considerar que seus conhecimentos não são uma nova proposta de educação:

(...) é importante esclarecer que elas não propõem uma nova pedagogia nem prometem soluções definitivas para as dificuldades da aprendizagem. Podem, contudo, colaborar para fundamentar práticas pedagógicas que já se realizam com sucesso e sugerir ideias para intervenções, demonstrando que as estratégias pedagógicas que respeitam a forma como o cérebro funciona tendem a ser mais eficientes. Os avanços das neurociências possibilitam uma abordagem mais científica do processo ensino-aprendizagem, fundamentada na compreensão dos processos cognitivos envolvidos (COSENZA; GUERRA, 2011, p. 142-143).

Assim, cabe ressaltar que as contribuições da neurociência são de suma importância, mas a abordagem de ensino e aprendizagem é tarefa do educador. As ações pedagógicas em sala de aula podem ficar mais eficientes quando este conhece o funcionamento cerebral.

\section{CONCLUSÃO}

O conhecimento fornecido pelas neurociências pode indicar algumas direções, ainda que não exista uma receita única a ser seguida, mesmo porque cada ser humano tem sua individualidade e sofre interferências, tanto em relação ao seu contexto familiar, quanto social.

A aprendizagem significativa e motivadora é o resultado da interação entre a emoção e a cognição, ambas estão tão conectadas a um nível neurofuncional tão básico, que se uma não funcionar a outra é afetada consideravelmente (FONSECA, 2016).

Conhecer o funcionamento do cérebro humano, saber que as emoções participam positivamente do desenvolvimento humano, mas que também pode cerceá-lo é uma ferramenta imprescindível aos que lidam com o processo de aprendizagem. 
Por isso, o professor deve estar atento às reações emocionais de seus alunos porque elas podem servir tanto para o sucesso quanto para o fracasso.

Quando se fala em emoção e aprendizagem, quer-se chamar atenção para as emoções de mão dupla. Não somente as sentidas por quem aprende, e sim para o binômio docente/discente, pais/filhos, enfim para todos os relacionamentos sociais, pois somos seres em construção e aprendemos todos os dias.

Já é sabido que quanto maior a carga emocional, maior será o nível de conteúdo armazenado, então o que precisamos é praticar mais as emoções positivas (entusiasmo, curiosidade, envolvimento, desafio), enquanto as negativas (ansiedade, apatia, medo, frustração) devem ser evitadas.

Espera-se que este trabalho possa contribuir para que novas pesquisas sejam implementadas sobre o assunto, sobretudo as de campo.

\section{REFERÊNCIAS}

ABRANTES, Pedro. De como escrevemos a vida e a vida se inscreve em nós: um estudo da socialização através da análise de autobiografias. Educ. Soc., Campinas, v. 35, n. 126, p. 111-127, mar. 2014. Disponível em $<$ http://www.scielo.br/scielo.php?script=sci_arttext\&p id $=$ S0101-73302014000100007\&lng=pt\&nrm=iso $>$.

CARVALHO, Fernanda Antoniolo Hammes de. Neurociências e educação: uma articulação necessária na formação docente. Trab. educ. saúde (Online), Rio de Janeiro, v. 8, n. 3, p. 537-550, nov. 2010. Disponível em $<$ http://www.scielo.br/scielo.php?script=sci_arttext\&p id=S1981-77462010000300012\&lng=pt\&nrm=iso $>$. COSENZA, Ramon M., Guerra, Leonor B.

Neurociência e educação: como o cérebro aprende. Leonor B. Guerra - Porto Alegre: Artmed, 2011.
COSENZA, Ramon M. Fundamentos de Neuroanatomia. 4. ed. - Rio de Janeiro: Guanabara Koogan, 2012.

ESPERIDIAO-ANTONIO, Vanderson et al . Neurobiologia das emoções. Rev. psiquiatr. clín., São Paulo, v. 35, n. 2, p. 55-65, 2008 . Available from

<http://www.scielo.br/scielo.php?script=sci_arttext\&p $\mathrm{id}=$ S0101-60832008000200003\&lng=en\&nrm=iso >

FERNANDES, Cleonice Terezinha et al .

Possibilidades de aprendizagem: reflexões sobre neurociência do aprendizado, motricidade e dificuldades de aprendizagem em cálculo em escolares entre sete e 12 anos. Ciênc. educ. (Bauru), Bauru, v. 21, n. 2, p. 395-416, jun. 2015.

Disponível em

<http://www.scielo.br/scielo.php?script=sci_arttext\&p $\mathrm{id}=\mathrm{S} 1516-73132015000200009 \& \operatorname{lng}=\mathrm{pt} \& \mathrm{nrm}=\mathrm{iso}>$.

FONSECA, Vitor da. Importância das emoções na aprendizagem: uma abordagem neuropsicopedagógica. Rev. psicopedag., São Paulo, v. 33, n. 102, p. 365-384, 2016. Disponível em

$<$ http://pepsic.bvsalud.org/scielo.php?script=sci_arttex t\&pid=S0103-

$84862016000300014 \& \operatorname{lng}=$ pt\&nrm $=$ iso $>$.

Lent, Robert. Cem bilhões de neurônios? Conceitos fundamentais de neurociências. 2. ed. - São Paulo: Editora Atheneu, 2010.

PEREIRA, Wilza Rocha et al . Emotional competencies in the process of teaching and learning in nursing, from the perspective of the neurosciences. Rev. Latino-Am. Enfermagem, Ribeirão Preto , v. 21, n. 3, p. 663-669, June 2013. Available from

<http://www.scielo.br/scielo.php?script=sci_arttext\&p $\mathrm{id}=$ S0104-11692013000300663\&lng=en\&nrm=iso >

PORTES, Daniella Soares. A importância das neurociências na formação do professor de inglês. Rev. psicopedag., São Paulo, v. 32, n. 98, p. 168-181, 2015 . Disponível em

<http://pepsic.bvsalud.org/scielo.php?script=sci_arttex t\&pid=S0103-

$84862015000200007 \& \operatorname{lng}=$ pt\&nrm=iso $>$.

RAMOS, Angela Souza da Fonseca. Dados recentes da neurociência fundamentam o método "Brainbased learning". Rev. psicopedag., São Paulo, v. 31, n. 96, p. 263-274, 2014. Disponível em <http://pepsic.bvsalud.org/scielo.php?script=sci_arttex t\&pid=S0103-

$84862014000300004 \& \operatorname{lng}=$ pt\&nrm $=$ iso $>$.

VENTURA, Dora Fix. Um retrato da área de Neurociência e comportamento no Brasil. Psic.: 
Teor. e Pesq., Brasília , v. 26, n. spe, p. 123-129,

2010. Available from

<http://www.scielo.br/scielo.php?script=sci_arttext\&p

$\mathrm{id}=\mathrm{S} 0102-37722010000500011 \& \operatorname{lng}=\mathrm{en} \& \mathrm{nrm}=\mathrm{iso}$ >

\section{Clecilene Carvalho}

Graduanda em Enfermagem. Universidade Vale do

Rio Verde.

clecilene@globo.com

Dejanir José Campos Júnior

Mestre em Educação pela Universidade Vale do Rio

Verde - UninCor.

Docente da Universidade Vale do Rio Verde.

dejanir.junior@unincor.edu.br

Gleicione Aparecida Dias Bagne de Souza

Doutora em Desenvolvimento Curricular pela

Universidade do Minho - Portugal

Docente da Universidade Vale do Rio Verde -

UninCor.

gleici@unincor.edu.br 